\title{
Analysis of the risk Identification Stage in Project Management
}

\author{
Hanna Soroka-Potrzebna \\ University Of Szczecin, Poland
}

\begin{abstract}
The reality that surrounds us, which is dynamically changing, creates huge opportunities for development, but at the same time increases the risk of making decisions. Projects, in comparison with other areas of activity, are associated with a higher level of risk due to their uniqueness. In addition, the implementation of most projects entails high investment outlays, in the absence of full knowledge about future project implementation periods. All these factors force project teams, and above all project managers, to apply appropriate risk identification methods. The article aims to compare the risk identification stage in the project management process used by project teams with the recommendations of experts. For this purpose, an analysis of surveys and interviews was used. The results of the conducted research allowed to show: how the risk is perceived, what risks particular attention is paid to, whether risk identification before the start of the project is important and what methods are used and recommended for this purpose.
\end{abstract}

Keywords: project manager; experts; comparing; methods; surveys 